discussion of subjects such as the mechanism of action of psychotropic drugs, the operation of genetic factors, the role of the opiate receptors and endorphins, nutritional factors and similar topics. The current interest in this approach is indicated by the establishment of separate Societies for Biological Psychiatry in the USA and in other countries and by the Worid Congresses of Biological Psychiatry, the second of which will be held in Barcelona this year.

A possible argument against this proposal is that Biological Psychiatry is included in and forms a part of the fields of other Specialist Sections which have already been formed. However, the advantages of having a separate Section for Biological Psychiatry appear to outweigh objections of that kind. A Section of this kind might in fact be expected to exert a unifying influence by bringing together members of other Sections and developing lines of thought that are relevant to other specialist fields.

If there are a sufficient number of members of the College who would support this proposal the first step will be to arrange a meeting to consider the setting up of a Group. May I therefore ask any Members who are interested in the proposal and who might wish to join such a Group to let me know their views. I should be glad also to have any suggestions that College members may like to make as to who might be the Chairman and Secretary of the Group.

Derex Richter

Deans Cottage,

Walton-on-the-Hill,

Tadworth, Surrey KT20 $7 T T$

\section{THE WERNICKE/KORSAKOV SYNDROME}

Dear Sir,

In the course of a biochemical study of the Wernicke/Korsakov syndrome, I have investigated a pair of identical twins-one with the disease, the other normal. Such cases appear to be excessively rare but are of importance for the research.

I would be grateful if any of your readers who might know of such identical twin material would inform me and perhaps allow me to study them biochemically.

The Maudsley Hospital,

Denis Leigh

Denmark Hill,

London $\mathrm{SE}_{5} \mathrm{A8Z}$

\title{
MYTHS AND 'MIND'
}

A reply to Dr Grumpton's article (Bulletin, March, p 4I) by Tony Smythe of MIND will be published in a forthcoming issue.

\section{THE UNIVERSITY OF MANCHESTER FACULTY OF MEDICINE}

Registered medical practitioners are invited to apply for a course in preparation for the degree of Master of Science (Psychiatry), starting in October 1978. The course will consist of part-time instruction during nine university terms. For the first two years there will be two days teaching every week in biological, clinical, social and psychological aspects of psychiatry and the methodology or research. The candidate will be examined at the end of the second year and will present a thesis at the end of the third.
Candidates should normally hold training posts at one of the psychiatric units in the Manchester region. Vacancies for such posts will be advertised in the medical press in April.

Further particulars can be obtained from Professor D. P. Goldberg, Department of Psychiatry, University Hospital of South Manchester, West Didsbury, Manchester M20 8LR, to whom application should be made as soon as possible. 